\title{
The Comparison of Attachment Styles in People with and Without
}

\section{Coronary Artery Disease}

\author{
Fereshteh Oladi $i^{1,2,{ }^{*}}$ and Mahmoud Dargahi ${ }^{2}$ \\ ${ }^{1}$ Department of Psychology, Torbat-e Jam Branch, Islamic Azad University, Torbat-e Jam, Iran \\ ${ }^{2}$ Interventional Cardiologist, Razavi Hospital, Mashhad, Iran \\ "Corresponding author: Department of Psychology, Torbat-e Jam Branch, Islamic Azad University, Torbat-e Jam, Iran. Tel: +98-9153380701, Email: fereshteh_oladi@yahoo.com
}

Received 2017 August 15; Revised 2017 December 10; Accepted 2018 January 20.

\begin{abstract}
Objectives: The present study compared attachment styles in patients with coronary artery disease (CAD) and healthy controls (non-CAD subjects).

Methods: This was a descriptive study with an ex-post facto design. The sample included 60 people (30 patients with CAD and 30 healthy controls), attending the office of an interventional cardiologist in Mashhad, selected by a convenience sampling method. They completed the adult attachment questionnaire. Data were analyzed using multivariate analysis of variance.

Results: The results of multivariate analysis of variance revealed that there was a significant difference in attachment styles between CAD patients and healthy controls so that healthy controls in the secure attachment style and CAD patients in the insecure attachment styles had a higher score.

Conclusions: The findings confirm that attachment styles are more insecure in CAD patients than in healthy people. These results suggest that insecure attachment styles increase the risk of coronary heart disease.
\end{abstract}

Keywords: Coronary Artery Disease, Attachment Styles, Cardiac Patients

\section{Background}

Coronary artery disease (CAD) refers to narrow or blocked arteries and vessels that provide oxygen and nutrients to the heart. It is caused by atherosclerosis, an accumulation of fatty materials on the inner linings of arteries (1). This general term is also applied to types of diseases caused by coronary artery blockage or narrowing (arteries are blood vessels that carry blood away from the heart to the body). When arteries are narrowed or blocked, the flow of blood transmission and delivery of food and oxygen to the heart muscle are slowed or stopped. In the state of heart blockage and slow blood flow, a severe pain occurs around the chest and arm, called angina pectoris, and when the artery is completely blocked, the heart nutrition in that part is severely interrupted, resulting in the heart attack. Should we be concerned about is the increasing growth-rate of this disease. Results of recent studies inside and outside the country suggest increases in the incidence of cardiovascular disease so that this disorder is considered the leading cause of premature death in $\operatorname{Iran}(2,3)$.

According to the conducted studies, cardiovascular disease is the common cause of mortality in the country, accounting for around $46 \%$ of the total deaths. In Iran, an estimated 15 million people $-21 \%$ of the total populationare affected by cardiovascular diseases (4).
New investigations show that cardiovascular diseases are preventable by $80 \%$ through controlling and treating predisposing risk factors (4). Thus, it can be claimed that investigating and identifying the variables underlying predisposing risk factors for the heart disease is among the most essential attempts. Researchers have made extensive efforts to conceptualize and measure emotional vulnerabilities that have a share in the development of medical disorders in general and cardiovascular diseases in particular. There is some evidence suggesting that several psychosocial factors are associated with cardiovascular diseases. These factors consist of education level, income, marital status, social support, stress, anxiety, depression, pessimistic hostility, and anger (5).

A psychological vulnerability factor that has attracted widespread theoretical attention in contemporary work on the etiology of cardiovascular disease includes attachment style. Attachment style is one of the most important factors affecting interpersonal interactions, which is developed in childhood and continues in the next ages with regard to the environment in which it has evolved (6). According to (7), attachment influences social transformation and psychological functioning in life. Hence, he believed that attachment is the basis of children's emotional development. He also argued that attachment is a primary 
need and is not derived from any other needs (8).

Attachment behavior is applied to approaching the attachment image and attachment bond refers to the emotional aspect of this relationship. This bonding is not necessarily two-sided but is a relationship established between a person and someone else (9). In the definition of attachment, they referred to the concept of bonding and believed that bonding is the process of forming an emotional connection, which is the attachment. Bonding, therefore, involves a set of behaviors that will help make an emotional connection. They also stated that asafe and secure attachment occurs when the mother shows that she is safe and loved and has empathy. These children freely keep a distance from their mother but constantly monitor the position of their mother and her whereabouts. When others hug them, they show a positive response and when they put them down, they resume with the play and exploration activities. Secure attachment is an important aspect of social-emotional development in which the child uses his/her mother as a safe base for the exploration of the outer world (9).

One of the attachment theory principles emphasizes that primary attachment relationships affect the individual's performance during his/her life. Hazan and Shaver (10) examined the attachment theory in adulthood and showed that attachment styles last forever and the issue of attachment affects the relationships of adults, spouses, and friends in addition to mothers. Therefore, at any age, the individuals' attachment style can be determined as secure, avoidant, and anxious-ambivalent with respect to the quality of their attachment to the significant people of their life (11).

The secure pattern involves people with a positive attitude toward themselves and others. Secure individuals feel comfortable getting close to others and welcome the support of others. They generally feel that they are worth the love and affection of others and thus expect to be well treated in close relationships. People with avoidant attachment have a negative view of others and do not tend to be close and intimate with others. Indeed, they are afraid of seeking affection and intimacy since they are constantly afraid of being rejected by others. Therefore, they do not consider themselves worthy of the love and affection of others in interpersonal relationships. They expect others to keep a distance from them or even reject them. On the other hand, people with anxious-ambivalent attachment have a negative attitude toward themselves despite having a positive attitude toward others. They are looking for the closeness and attention of others and may even have the states of adhesion and annoyance in close relationships. Nevertheless, they generally feel that they value others better than they value themselves.
Research has shown that secure attachment in adulthood is closely related to many positive attributes and psychological health, and secure couples in stable marriages are happier compared to insecure couples in stable marriages (12). On the other hand, insecure attachment styles (avoidant and anxious-ambivalent) are associated with disintegration of romantic relationships (13) and marriage failure (11). Davis (14) found that anxious women and avoidant men tend to look at their relationships negatively despite the strength and stability of their relationships. Further, among married couples, the results indicated that anxious-ambivalent attachment is related to stable but unhappy relationships.

Investigations have demonstrated that psychological states and traits associated with insecure attachment styles are related to the risk of heart diseases. The emotions that people experience with insecure attachment styles have a direct impact on their both mental and physical health. Emotions such as anxiety, depression, and even hostility that individuals experience with avoidant and anxious-ambivalent attachments styles in various social interactions are associated with the incidence of the cardiovascular syndrome. Studies indicated that patients with cardiovascular disorders have a history of the long-term experience of anxiety and depression before they develop cardiovascular diseases (15).

Schmidt et al. (16), in a study indicated that secure attachment styles not only reduce the risk of heart disease but also improve the manner of dealing with the cardiovascular disease in case of occurrence. People with secure attachment styles use more flexible coping strategies for dealing with cardiovascular diseases compared to individuals with insecure attachments styles. Additionally, insecure attachment styles are predictors of the risk of cardiovascular disorders.

\section{Objectives}

Based on the foregoing, it seems that attachment styles of cardiac patients are different from those of healthy people. Hence, this study intended to compare attachment styles in CAD patients and non-CAD subjects.

\section{Methods}

\subsection{Type of Research}

According to the purpose of the study, in terms of the method, this was an applied research with a descriptive and ex-post facto design. The study employed two populations including CAD patients and non-CAD people to be 
compared in three attachment styles (independent variables). Regarding the numbers of dependent and independent variables, multivariate analysis of variance was used. Demographic characteristics of the two populations are presented in Table 1.

\begin{tabular}{lcc}
\hline Table 1. Demographic Characteristics & & \\
\hline Variables & Patients with CAD & Non-CAD People \\
\hline Range of age & 34 to 61 & 34 to 61 \\
\hline Male (\%) & 57 & 59 \\
\hline Female (\%) & 43 & 41 \\
\hline Married (\%) & 61 & 58 \\
\hline High school diploma (\%) & 73 & 69 \\
\hline Higher education (\%) & 27 & 31 \\
\hline
\end{tabular}

Population, sample, and sampling method: The statistical population of interest included 60 people. Using a convenience sampling method, a sample of 30 patients with CAD was selected from the available population attending the office of an interventional cardiologist in Mashhad with regard to the inclusion criteria. Then, a sample of the same number as the matched control group was chosen from among non-CAD people who met the following criteria as homogeneity factors between groups: (1) aged between 34 to 61 years, (2) being a family member of CAD people and, (3) having at least a high school diploma.

\subsection{Materials and Procedure}

In this study, adult attachment scale by Collins and Read (17) was used to measure the attachment style of the sample. The scale was developed by decomposing the original three prototypical descriptions (10) into a series of 18 items. The scale consists of 18 items scored on a 5point Likert-type scale. It measures adult attachment styles named "Secure", "Anxious" and "Avoidant". This scale comprises the self-assessment of relationship-building skills and self-description of the method of developing attachment relationships with close attachment figures. There are 18 items, six on each dimension, scored on a scale from 1 to 5 (1- not at all characteristic of me, 5- very characteristic of me). By factor analysis, three subscales were identified, each including six items. The three subscales include dependence, closeness, and anxiety (17). The anxiety subscale (A) corresponds to anxious-ambivalent attachment style and the closeness subscale $(\mathrm{C})$ is a bipolar dimension that basically places secure and avoidant descriptions against each other. Thus, closeness (C) is consistent with secure attachment and the dependence subscale (D) is almost opposite of the avoidant attachment. Questions $6,1^{*}, 8^{*}, 13,12$, and $17^{*}$ evaluate the secure attachment. Questions $5^{*}, 2,16$,
14,7 , and $18^{*}$ measure the avoidant attachment and finally, questions 4,3, 9,10,11, and 15 assess the anxious-ambivalent attachment. Questions marked with an asterisk must be scored inversely before adding. Scores related to the six items of each scale are summed to obtain the subscale total score. Collins and Read (17) suggested that the subscales of closeness, dependence, and anxiety remained stable within two and even eight months and concerning the reliability of the Collins and Read's adult attachment scale, the reliability coefficient of the attachment scale, for 3 attachment styles "Secure", "Anxious" and “Avoidant”, was reported as $0.82,0.83$, and 0.80 , respectively (17). Moreover, Pakdaman (18) in a study investigating an Iranian population assessed validity as acceptable and described Cronbach's alpha to be equal to or more than 0.80 for each subscale of this questionnaire in all cases. Therefore, the test enjoys a high level of validity $(17,18)$.

\section{Results}

The attachment questionnaire was handed out to each one of the sample members and the results were analyzed descriptively and inferentially. Multivariate analysis of variance (MANOVA) was used to compare the mean score of attachment test components in two groups of patients and non-CAD people. Before implementing MANOVA, the assumptions of normal distribution and homogeneity of variances were analyzed by the Kolmogorov-Smirnov test and the Levene test, respectively. The results showed that the distribution is normal, variances are homogenous, and therefore, there was the possibility of implementing MANOVA.

Descriptive indicators of the data obtained from the analysis of the attachment questionnaire for each of groups separately, and results of the multivariate analysis of variance to compare the two groups are provided in Table 2 .

As can be observed, the anxious and avoidant attachment scores were significantly higher in patients with CAD than in non-CAD people. Besides, the secure attachment scores were considerably higher in non-CAD people than in patients with CAD. This difference will be discussed in detail in the next section.

Given the results in Table 2 obtained from the MANOVA test, it can be concluded that a significant difference existed between patients with $\mathrm{CAD}$ and non-CAD people in the secure attachment rate $\left(\mathrm{P}<0.01, \mathrm{~F}_{(1,58)}=18.148\right)$, in such a way that non-CAD people showed more secure attachment compared to coronary artery disease patients. Moreover, there was a significant difference between CAD patients and non-CAD people in the anxious attachment rate $\left(\mathrm{P}<0.001, \mathrm{~F}_{(1,58)}=21.507\right)$ so that $\mathrm{CAD}$ patients showed 


\begin{tabular}{|c|c|c|c|c|c|c|c|}
\hline Group & Mean \pm SD & Min. & Max. & $\mathbf{F}$ & P-Value & Impact Coefficient & Statistical Power \\
\hline Secure attachment & & & & 18.148 & 0.002 & 0.387 & 0.874 \\
\hline Patients with CAD & $17.55 \pm 6.20$ & 4.00 & 24.00 & & & & \\
\hline Non-CAD people & $21.53 \pm 6.64$ & 7.00 & 30.00 & & & & \\
\hline Anxious attachment & & & & 21.507 & 0.001 & 0.473 & 0.912 \\
\hline Patients with CAD & $20.40 \pm 5.81$ & 6.00 & 28.00 & & & & \\
\hline Non-CAD people & $14.86 \pm 4.56$ & 5.00 & 21.00 & & & & \\
\hline Avoidant attachment & & & & 13.336 & 0.031 & 0.241 & 0.672 \\
\hline Patients with CAD & $17.62 \pm 6.65$ & 8.00 & 25.00 & & & & \\
\hline Non-CAD people & $12.10 \pm 7.75$ & 5.00 & 24.00 & & & & \\
\hline
\end{tabular}

higher anxious attachment compared to non-CAD people. Further, a significant difference was observed between CAD patients and non-CAD people in the avoidant attachment rate $\left(\mathrm{P}<0.05, \mathrm{~F}_{(1,58)}=13.336\right)$ so that patients with $\mathrm{CAD}$ showed more avoidant attachment compared to non-CAD people.

\section{Discussion}

The present study sought to compare attachment styles in CAD patients and non-CAD people. The results indicated that CAD patients compared to non-CAD people obtained higher scores on the components of anxious and avoidant attachment as insecure attachment styles. Additionally, the results indicated that CAD patients compared to non-CAD people achieved lower scores on the component of the secure attachment style. This result indicates that patients with CAD developed the insecure attachment style in the initial relationships with their caregivers because they did not receive enough affection and in adulthood, the emotions associated with insecure attachment style prevailed in the emotional bonding that they established with relatives and close friends. These findings suggest that the insecure attachment style leads to the increased risk of heart diseases and on the contrary, the secure attachment style protects against the risk of heart diseases. These findings are consistent with the results obtained by Schmidt et al. (16), Hawkley et al. (19), Wang et al. (20), Molarius et al. (5), Troxel et al. (15), Everson-Rose and Lewis (21), Friedman and Rosenman (22), Consedine et al. (23), and Pietromonaco et al. (24) that referred to the effects of the insecure avoidant and anxious attachment styles and their associated emotions on the risk of heart diseases.

To explain what makes research findings reliable and valid, the impacts of attachment styles on psychological and physical health should be mentioned. Among the factors related to the insecure attachment styles considered as an important risk factor for cardiovascular diseases is the lack of social support. Individuals with the insecure attachment styles experience low social support and feel lonely compared to people with the secure attachment style because they lack the ability to establish long-term social relations (25). Investigations have demonstrated that young adults who felt lonely showed different cardiovascular system responses relative to those who felt less lonely (19). Besides, it seems that social support has a role in the development of heart diseases such that a study indicated that the progression of coronary artery obstruction was less in women with high levels of emotional and social support than in women with weaker social relations (20).

Since the relationship accompanied by the secure attachment style provides social support, securely attached individuals have a lower risk of cardiovascular diseases. However, the quality of emotional relationships is raised as a factor in this case. Women who have reported to be satisfied with their marriage have shown lower levels of several risk factors compared to women dissatisfied with their marriage. As a result, spouse and other social support resources may reduce the risk of death from the cardiovascular disease so that the patient is encouraged to achieve a healthy lifestyle and medical regimen by seeking medical care. Social support resources usually consist of family and spouse (15).

Moreover, stress, anxiety, and depression, which are the phenomena accompanied by the insecure-anxious attachment style, are associated with cardiovascular diseases; but these factors are also related to one another so that people with heart attacks experience more occupational and financial stresses and life events relative to ordinary individuals. Even after controlling other risk factors such as smoking and cholesterol, anxiety and depression are the factors that predict the creation and development 
of cardiovascular diseases (21).

In recent years, studies have suggested that some types of hostility and anger are the risk factors for cardiovascular diseases. Most investigations are related to the type A behavior pattern, including hostility, competitiveness, simultaneous engagement with a number of tasks and goals, and a constant sense of having little time (22). On the other hand, research has shown that people with the insecure-avoidant attachment styles experience more hostility in interpersonal relationships compared to securely attached individuals (26). Pessimistic hostility, which is characterized by an avoidant attachment style, is harmful to cardiovascular health and people who are distrustful of others and have the worst attitude toward humanity and interact with others with pessimistic hostility hurt themselves and their hearts. In addition, individuals who use anger as a response to their interpersonal issues have shown a higher risk of heart diseases (21).

Other studies have demonstrated that the hostility score of younger heart patients was 2.5 times higher than that of older patients. Hostility as a risk factor, in the long run, is raised even after a heart surgery and reduces life expectancy (23). Anxiety and depression in women are better predictors of cardiovascular diseases while hostility is a better predictor of cardiovascular diseases in men (23). Therefore, it can be concluded that probably the anxious attachment style in women and avoidant attachment style in men can lead to a heart disease.

As seen, people with the coronary artery disease had more insecure attachment styles compared to healthy individuals. Therefore, insecure attachment styles increase the risk of this fatal disease. According to the results of this research and previous studies on interventions and therapy methods to improve attachments styles in patients with $\mathrm{CAD}$, the incidence of coronary artery disease can be prevented by using prompt intervention and changing the attachment style of individuals; therefore, treatment sessions are recommended for improving their attachment styles. Moreover, because of the importance of attachments style, it is suggested investigating pregnant women and their husbands and conducting treatment sessions containing emotionally focused couple therapy (EFCT) to provide parents with the secure attachment style.

Furthermore, in patients with other diseases of heart failure, cardiomyopathy, and hypertension, probably insecure attachment styles increase the risk of this disease and so, extensive research in the future is required. In addition, it is recommended that studies be carried out on attachments styles in patients with other chronic diseases, such as diabetes mellitus and cancer patients.

Using a convenience method in selecting the sample and recruiting the small number of subjects may limit the generalizability of the results. Conducting research on larger samples with follow-up treatment designs can help generalize results and confirm the stability of findings over time.

\section{References}

1. Sarafino EP, Smith TW. Health Psychology: Biopsychosocial Interactions. illustrated ed. John Wiley and Sons; 2014.

2. Sadeghi M, Ruhafza H, Shirani S, Tabib AA, Aghdak P, Hosseini S. The Prevalence of Coronary Artery Disease: Isfahan Healthy Heart Program (IHHP). ARYAJ. 2006;2(2).

3. Aghasadeghi K, Zarei-Nezhad M, Keshavarzi A, Mehrabani D. The prevalence of coronary risk factors in Iranian lor migrating tribe. Arch Iran Med. 2008;11(3):322-5. [PubMed: 18426325].

4. Nohi E, Abdolkarimi M, Rezaeian M. [Quality of Life and Its Relationship with Stress and Coping Strategies in Coronary Heart Disease Patients].J Rafsanjan U Med Sci. 2011;10(2):127-37. Persian.

5. Molarius A, Seidell JC, Sans S, Tuomilehto J, Kuulasmaa K. Waist and Hip Circumferences and Waist-Hip Ratio in 19 Populations of the WHO MONICA Project. Int J Obesity. 1999;23(2):116-25. doi: $10.1038 /$ sj.ijo.0800772.

6. Butzer B, Campbell L. Adult attachment, sexual satisfaction, and relationship satisfaction: A study of married couples. Pers Relationship. 2008;15(1):141-54. doi: 10.1111/j.1475-6811.2007.00189.x.

7. Bowlby J. A Secure Base: Clinical Applications of Attachment Theory. 23. reprint ed. Londan and New York: Taylor and Francis; 2005.

8. Bowlby J, Bowlby R. The Making and Breaking of Affectional Bonds. illustrated, reprint ed. Londan and New York: Taylor and Francis; 2005.

9. Roberts A, Pistole MC. Long-Distance and Proximal Romantic Relationship Satisfaction: Attachment and Closeness Predictors. J Coll Counsel. 2009;12(1):5-17. doi: 10.1002/j.2161-1882.2009.tb00036.x.

10. Hazan C, Shaver P. Romantic love conceptualized as an attachment process. J Pers Soc Psychol. 1987;52(3):511-24. [PubMed: 3572722].

11. Banse R. Adult Attachment and Marital Satisfaction: Evidence for Dyadic Configuration Effects. J Soc Pers Relat. 2016;21(2):273-82. doi: $10.1177 / 0265407504041388$.

12. Hinnen C, Sanderman R, Sprangers MA. Adult attachment as mediator between recollections of childhood and satisfaction with life. Clin Psychol Psychother. 2009;16(1):10-21. doi: 10.1002/cpp.600. [PubMed: 19165809].

13. Berry $\mathrm{K}$, Barrowclough $\mathrm{C}$, Wearden A. A review of the role of adult attachment style in psychosis: unexplored issues and questions for further research. Clin Psychol Rev. 2007;27(4):458-75. doi: 10.1016/j.cpr.2006.09.006. [PubMed: 17258365].

14. Davis PJ. Gender differences in autobiographical memory for childhood emotional experiences. J Pers Soc Psychol. 1999;76(3):498-510. [PubMed: 10101879].

15. Troxel WM, Matthews KA, Gallo LC, Kuller LH. Marital quality and occurrence of the metabolic syndrome in women. Arch Intern Med. 2005;165(9):1022-7. doi: 10.1001/archinte.165.9.1022. [PubMed: 15883241]

16. Schmidt S, Nachtigall C, Wuethrich-Martone O, Strauss B. Attachment and coping with chronic disease. J Psychosom Res. 2002;53(3):763-73. [PubMed: 12217450].

17. Collins NL, Read SJ. Adult attachment, working models, and relationship quality in dating couples. J Pers Soc Psychol. 1990;58(4):644-63. [PubMed: 14570079].

18. Pakdaman S. Investigating the Relationship Between Attachment style and Sociopolitical in Adolescence. J Psychol Sci. 2001;47(9):25-33.

19. Hawkley LC, Burleson MH, Berntson GG, Cacioppo JT. Loneliness in everyday life: cardiovascular activity, psychosocial context, and health behaviors. J Pers Soc Psychol. 2003;85(1):105-20. [PubMed: 12872887]. 
20. Wang HX, Mittleman MA, Orth-Gomer K. Influence of social support on progression of coronary artery disease in women. Soc Sci Med. 2005;60(3):599-607. doi: 10.1016/j.socscimed.2004.05.021. [PubMed: 15550307].

21. Everson-Rose SA, Lewis TT. Psychosocial factors and cardiovascular diseases. Annu Rev Public Health. 2005;26:469-500. doi: 10.1146/annurev.publhealth.26.021304.144542. [PubMed: 15760298].

22. Friedman M, Rosenman RH. Type A Behavior Pattern: its association with coronary heart disease. Ann Clin Res. 1971;3(6):300-12. [PubMed: 5156890].

23. Consedine NS, Magai C, Chin S. Hostility and Anxiety Differentially Predict Cardiovascular Disease in Men and Women. Sex Rol. 2004;50(1):63-75. doi: 10.1023/B:SERS.0000011073.44105.6f.
24. Pietromonaco PR, Uchino B, Dunkel Schetter C. Close relationship processes and health: implications of attachment theory for health and disease. Health Psychol. 2013;32(5):499-513. doi: 10.1037/a0029349. [PubMed: 23646833]. [PubMed Central: PMC3648864].

25. Makinen JA, Johnson SM. Resolving attachment injuries in couples using emotionally focused therapy: steps toward forgiveness and reconciliation. J Consult Clin Psychol. 2006;74(6):1055-64. doi: 10.1037/0022-006X.74.6.1055. [PubMed: 17154735].

26. Burchell JL, Ward J. Sex drive, attachment style, relationship status and previous infidelity as predictors of sex differences in romantic jealousy. Pers Indiv Differ. 2011;51(5):657-61. doi: 10.1016/j.paid.2011.06.002. 